\title{
The global usage rate of bed nets during the last ten years: a systematic review and meta-analysis
}

\section{Mona Hanafy Mahmoud}

Ain Shams University Faculty of Medicine

\section{Ruth L. Chikuni}

School of Tropical Medicine and Global Health, Nagasaki University

Gehad Mohamed Tawfik

Ain Shams University Faculty of Medicine

Asmaa Ibrahim Rashidy

Aswan University

Ahmed Elsayad Salama

Al-Azhar University Faculty of Medicine

Loai Jalal Sulaiman

Alexandria University

Chikuni Gelly Simakechula

Schoolf Tropical Medicine and Global Health , Nagasaki University

Ahmed Magdy Sayed

Al-Azhar University

Mahmoud Ali AlFadaly

Al-Azhar University Faculty of Medicine

\section{Balqees Mahmoud AL-Manaseer}

Jordan University of Science and Technology Faculty of Medicine

\section{Seif Mahmoud Abdelghany}

Fayoum University Faculty of Medicine

\section{Fatma Elzahraa Yasser Ali}

Zagazig University Faculty of Human Medicine

\section{Mohamed M. Elsergany}

Port Said University, Faculty of Medicine

\section{Rana Hesham Shakaria}

Mansoura University Faculty of Medicine

Hadeir Said Mohamed

Al-Azhar University Faculty of Medicine

\section{Yara Mahmoud Mohamed}

Misr University for Science and Technology College of Medicine Ahmed Mohamed Khalifa 
Alexandria Medicine: Alexandria University Faculty of Medicine

\section{Marwa Isa Biala}

University of Tripoli Faculty of Medicine

Abdelrahman Hamdy Abdelrahman

Aswan University

Mahmoud Abdulmonem Abulnaga

Al-Azhar University Faculty of Medicine

\section{Ali Ahmed-Fouad Abozaid}

Ain Shams University Faculty of Medicine

\section{Mostafa Khaled Abdelsattar}

Cairo University Kasr Alainy Faculty of Medicine

\section{Loc Le Quang}

University of Medicicne and Pharmacy at Ho Chi Minh City

\section{Nguyen Dinh Thuong}

Dalhousie University Faculty of Medicine

\section{Mohammed Salah Desokey}

Aswan University

\section{Esraa Mahmoud Mostafa}

Port Said University Faculty of Medicine

\section{Sheikh Mohammed Shariful Islam}

Deakin University

\section{Kazuhiko Moji}

School of Tropical Medicine and Global Health , Nagasaki University

Nguyen Tien Huy ( $\nabla$ nguyentienhuy@tdtu.edu.vn )

Institute of Tropical Medicine (NEKKEN), Nagasaki University https://orcid.org/0000-0002-9543-9440

\section{Research article}

Keywords: BED NETS, ITN, MALARIA, OWNERSHIP, USAGE

Posted Date: October 16th, 2020

DOI: https://doi.org/10.21203/rs.3.rs-90881/v1

License: (9) This work is licensed under a Creative Commons Attribution 4.0 International License. Read Full License 


\section{Abstract}

Background: Malaria is an endemic disease especially in tropical areas transmitted by Anopheles mosquito through their bites. Therefore, bednets are one of the best methods for protection against their bites. However, many regions have limited access to bednets and limited knowledge about their importance.

Objectives: Primary objectives were to estimate bednet possession and usage rate for last 10 years. Secondary objectives aimed to calculate the prevalence of specific bednets' types.

Methods: We performed an electronic search on 12 databases, and 106 studies were included obeying the criteria.

Results: 106 studies included in our meta-analysis. Study participants were mostly from Africa while a few from Asia and southern America. Overall bednet ownership rate per households among countries was $72.1 \%$ (95\% Cl: $62.9-79.7)$ while per individuals was 52.5\% (95\% Cl: $37-67.4)$. In addition, overall bednet usage rate per households among countries was $41.2 \%$ (95\% Cl: 25.1-59.3) same as bednet usage per individuals.

Conclusion: Our study suggests that the bednet ownership and usage rate among different countries are less satisfactory, hence not maximizing the potential benefit of the bed net. There is a crucial need to increase awareness towards the bednet usage across endemic areas and implement programs for free distribution of bednets.

\section{Background}

Malaria envelops about 90 countries all over the world, especially those located within tropical and subtropical regions where malaria blossoms with stagnant water and warm climate.[1] The principal causative organism of malaria in humans is a parasite called plasmodium which includes $P$. falciparum, $P$. vivax, P. malariae, $P$. ovale, and, $P$. knowlesi, which is transported through insects, chiefly the anopheles genera. $[2,3]$ Notably, diagnosing malaria is too difficult even for experts which exacerbates its danger on humans.[3] Malaria with poverty is the key factor for about 438,000 causalities annually, most of them among African kids.[4] While there are numerous drugs to treat this plasmodium infection, the developing resistance is hindering success towards eradicating this dilemma. Consequently, a great portion of the success in eradicating malaria lies within developing an anti-malarial innovative treatment. However, bed nets are the main vector control intervention still used against malaria.[5]

Bed net is an open mesh which covers sleeping people as a physical barrier to limit insects and flies.[6] The perspective of a bed net was developed later to include nets which are treated with insecticides to provide both chemical and physical barriers against vectors resulting in further protection against vectorborne diseases. Interestingly, some of these treated bed nets can be effective for a few years, namely the Long-Lasting Insecticidal Net (LLIN). Clinically, the usage of bed nets had a considerable impact on 
reducing infection with malaria.[7] A Cochrane review of 23 trials proved that using bed nets has cut down the prevalence of malaria and other vector-borne diseases by $17 \%$.[8] Insecticide-treated nets (ITN) succeeded to save about $50 \%$ more lives as estimated by another study.[9]

The impact of such bed nets urged volunteers, NGOs and medical organizations to support endemic areas with nets; resulting in the spread of nets to reach unprecedented rates. However, more work is needed to cover all potential targets of vector-borne disease. Unfortunately, the coverage rate of bed nets in many countries is low, for different reasons including the unavailability in many areas.[10] Also, the reported prevalence of bed nets may be biased due to the difference between the possession rate and the usage rate which could result in different outcomes of the implementation of bed nets. Therefore, our study aims to evaluate the true possession and usage rate of bed nets globally to alert health organizations to take actions.

\section{Methods}

\section{Study protocol registration}

According to recommendations of Cochrane Handbook for Systematic Reviews of Interventions and the PRISMA (Preferred Reporting Items for Systematic Reviews and Meta-Analyses), our study was performed as shown in the PRISMA checklist (Supplementary Table 1).[11, 12] A pre-protocol of methods has been registered with the International prospective register of systematic reviews (PROSPERO) website (CRD42019122019) on April $2^{\text {nd }}, 2019$.

\section{Search strategy}

In October 2018, we conducted a systematic search of 12 electronic databases including PubMed, Scopus, Web of Science (ISI), EMBASE, Google Scholar, VHL, GHL, meta Register of Controlled Trials (mRCT), Cochrane, POPLINE, NYAM, and SIGLE. The search terms employed was: (bednet OR bednets OR "bed net" OR "bed nets" OR "insecticide-treated" OR ITNs OR ITN OR "pesticide-treated") AND (coverage OR use OR usage). Including only papers published from 2008; no human filter, nor restriction applied regarding age, gender, ethnicity, language, or country was used. The search results from the databases mentioned above are available in Supplementary Table 2.

\section{Study eligibility criteria and study selection}

After removing duplicates using Endnote X8.1, studies were included according to the following criteria: community-based studies that investigated the rate of bed net usage in the population from 2008 to 2018. Case reports, abstracts only, reviews, letters, editorials, books, conferences, studies with unextractable data or these with insufficient data were excluded. Also, we excluded studies that involve specific subgroups including pregnant women, children of any specific age group, school-based, or hospital-based, infected population, specific ethnicity, etc. Also, studies with a duplicated data set and any studies that report data after bed net distribution were excluded. Three independents reviewers 
included or excluded the studies based on the title and the abstract first, followed by the full-text screening.

\section{Data extraction}

Three independent reviewers were responsible for data extraction from the included studies, and in case of conflict, consultation was supported. The extraction sheet was composed of three parts: baseline characteristics section, outcomes section and quality assessment. The first part included reference ID, study design, age and gender. The second part was outcomes of the study including usage rates of bed nets per each country and prevalence of specific bed net types. The last third part for NIH Quality Assessment Tool for Observational Cohort and Cross-Sectional Studies.

\section{Outcome measures}

Bed net ownership was defined as the number of individuals or households that own at least one bed net of any type but not necessarily using it. While bed net usage is defined as the number of households or individuals that use bed nets during sleep regardless of frequency of usage. Sometimes, sleeping under a bed net at the night before the survey is considered bed net usage. Our primary outcome was the prevalence of bed net ownership and usage rate globally. The secondary outcome was the prevalence of insecticide-treated nets or any special types of bed nets. Outcomes taken at any time before intervention or trial was included.

\section{Quality assessment}

Using NIH Quality Assessment Tool for Observational Cohort and Cross-Sectional Studies we assessed the quality of all included studies independently by three reviewers. The assessment of each domain was categorized as Yes (1), No (0), Other (CD, NR, NA) * "*CD, cannot determine; NA, not applicable; NR, not reported". A score of 10-14 indicated a good quality article, 5-9 for fair, and 1-4 for a poor-quality article. Any differences between our three independent reviewers were resolved by discussion and by consultation with a supervisor to reach a concordance if needed.

\section{Statistical analysis}

Analysis was carried out using Comprehensive Meta-analysis software. Heterogeneity was evaluated between the included studies by using the $Q$ statistic and $\mathrm{I}^{2}$ test. A p-value of less than 0.05 is considered statistically significant for heterogeneity. Pooled OR with the corresponding $95 \%$ confidence intervals $(95 \% \mathrm{Cl})$ was also to be calculated. Regarding weighting of the studies, we used a fixed-effects model when there was a lack of significant heterogeneity and used a random-effects model when there was heterogeneity between studies. Dichotomous data are presented as prevalence event rate with a $95 \%$ confidence interval $(\mathrm{Cl})$. The qualitative synthesis was performed to describe the clinical and methodological characteristics of the included studies. Data synthesis was done by three independent reviewers. The discrepancies between the reviewers were resolved by discussion with senior reviewers. 
Using the funnel plot and Egger's regression test we evaluated publication bias. If detected publication bias, we would add studies that may be missed by using the fill method.

\section{Results}

\section{Systematic search and its results}

The initial search resulted in 7036 articles from 12 databases. Of these, 2475 duplicated articles were excluded by endnote $X 8$. After the title and abstract screening stage, 2431 articles were excluded because they did not meet inclusion criteria, and 2130 full-text articles were screened to determine eligibility. Of these, we excluded 2045 articles for reasons shown in Figure 1. After adding 21 articles after the manual search stage, a total of 106 articles underwent full data extraction and were included for the final qualitative and quantitative analysis.

\section{Studies characteristics}

A total of 106 studies $[10,13-116][10,13-116]$ have been included in the systematic review and metaanalysis. ${ }^{10,13-116}$ Regarding study design, mainly cross-sectional studies were conducted and a representative population of all ages and gender were recruited to represent their communities or districts. Furthermore, most of the study population are from the African continent due to the high malaria state while the rest are from Asia and rarely southern America. Regarding quality assessment, there were 79 papers with fair quality, 16 papers with good quality whereas 13 papers had poor quality. All details are provided in Supplementary Table 3.

All 106 studies were included in the meta-analysis. The data firstly were divided into the household level and individual level as not all studies reported data in the same unit. Besides, each group underwent subgroup analysis, one according to different countries and the other according to the type of bed net used. Finally, a crude map was constructed with the above-mentioned data, reporting the prevalence of ownership and usage of bed nets among countries and a broad view among continents.

\section{Bed net household ownership}

In household level ownership, the overall ownership rate of bed net households was (event rate $=72.1 \%$, $95 \% \mathrm{Cl}:$ 62.9-79.7). Random effect model was used due to high heterogeneity: $12=99.907, \mathrm{P}$-value $<0.001$. The highest bed net household ownership rate was in Bangladesh (event rate=98.4\%, 95\% Cl: 89.4-99.8). On the other hand, the lowest ownership rate of bed net households was reported in Saudi Arabia (event rate $=22.1 \%$, 95\% Cl: 3.7-67.5) (Figure 2). The household ownership rate of each country illustrated in SupplementaryFigure 1, showed that all studies were conducted in only Africa and Asia.

For the subgroup of the type of bed net, the commonest type of owned nets was reported as long-lasting insecticides treated nets (LLINs), (event rate=78.3\%, 95\% Cl: 71.5-83.8), whereas insecticide-treated nets (ITNs) was the lowest reported, (event rate=62.9\%, 95\% Cl: 55.8-69.5) (Supplementary Figure 2) 


\section{Bed net individual ownership}

As regard to individual-level ownership rate, Meta-analyses of country subgroups showed that the highest bed net individual ownership rate was in Kenya (event rate=72.9\%, 95\% Cl: 64.7-79.9). On the other hand, the lowest ownership rate of bed net individual was reported in Uganda (event rate=14.7\%, 95\% Cl: 9.222.8). The overall ownership rate of bed net individual was $52.5 \%$ (95\% Cl: 37.0-67.4) (Figure 3).

For net-type subgroup, the analysis revealed that the most common individual owned type of bed net according to studies was bed net of non-specified type (event rate $=70.3 \%, 95 \% \mathrm{Cl}$ : 39.6-89.6), and the insecticide-treated nets (ITNs) was the most commonly owned bed net-type, especially in Kenya, (event rate $=74.0 \%, 95 \% \mathrm{Cl}:$ 71.4-76.4) (Supplementary Figure 3).

\section{Bed net household usage}

The analysis results for household usage rate revealed the highest bed net household usage rate was in Vietnam (event rate $=90.3 \%, 95 \% \mathrm{Cl}: 70.3-97.3$ ). On the other hand, the lowest bed net household usage rate was reported in be Ghana (event rate $=5.9 \%, 95 \% \mathrm{Cl}: 0.8-31.9$ ). And the overall usage rate of bed net households was $41.2 \%$ (95\% Cl: 25.1-59.3). The total households among all countries that use bed net are 13481 out of 35,224 with an event rate of about $41.2 \%$ which is almost half the ownership rate of 72.2\% (Figure 4). The household usage rate of each country was further illustrated in (Supplementary Figure 4).

For the type of bed net subgroups as shown in the Supplementary Figure 5, the highest rate found for household usage was of LLIN (event rate=52.6\%, 95\% Cl: 37.5-67.3), followed by any type (event rate $=41.3 \%, 95 \% \mathrm{Cl}: 25-59.7)$, and ITN (event rate=38.8\%, 95\% Cl: 23.8-56.2).

\section{Bed net individual usage}

Individual usage rate meta-analyses of relevant studies showed the highest rate in Vietnam (event rate $=90.3 \%, 95 \% \mathrm{Cl}: 70.3-97.3$ ) and the lowest rate in Ghana (event rate=5.9\%, 95\% Cl: 0.8-31.9). Moreover, the overall usage rate of bed net individual was $41.2 \%$ (95\% Cl: 25.1-59.3), which was lower than that of the individual ownership 58.2\% (Figure 5).

In the subgroup meta-analysis done for net types of individual usage, we saw the magnificent rise of usage of LLINs among people in various countries with the overall rate of 52.6\% (95\% Cl: $37.5-67.3)$, especially highest in Vietnam (event rate $=90.4 \%, 95 \% \mathrm{Cl}$ : 88.1-92.2) and lowest in India (Ntuku'2017) (event rate $=11.7 \%, 95 \%$ Cl: 11-12.5) (Supplementary Figure 6).

We detected publication bias (Supplementary Figure 7) by Egger's test with significant results ( $\mathrm{p}$-value= 0.02536) among 106 studies included in our meta-analysis. There were 20 studies with the risk of publication bias and this issue was resolved by the fill method.

\section{Discussion}


Our systematic review and meta-analysis explained that the low prevalence rate of bed net usage may undermine the clinical effectiveness of bed nets as the usage of bed nets is significantly lower than the ownership rates in households.

Notably, Eng et al. found that children, who are occupants of houses with an unhanged bed net, were about 5.1-16.1\%, while children, who were occupants of houses with hanged bed nets but did not sleep under it, were about 4.3-16.4\%.[117] Therefore, researchers should take the reported rates with much caution as these results may misguide them. The reason behind non-use nets may be a result of different social factors including, for instance, the number of family members in the household. Therefore, we need to understand human behavior before the optimization of medical intervention to eliminate endemic diseases like malaria.[118]

Regarding household's ownership, we found that Saudi Arabia was the lowest country owning bed nets while Bangladesh reported the highest ownership of bed nets. This result is raising a question about the reason behind having a rich country like Saudi Arabia in the tail of countries having bed nets. A study figured out that Saudi households have good knowledge about malaria and prevention measures, however, they recommended improvement for the practices. [61] For an explanation for this low percentage, we need to consider the low burden of malaria in SA compared to the burden of Malaria in Bangladesh.[119] Also, a study found that there is a significant difference between Saudi/Non-Saudi households in obtaining nets.[61] Simply, we cannot neglect the socio-economic factors when trying to explain human behavior towards protective measures like bed nets. Additionally, we need to know that the household as a word may cause a bias; as the house may hold a family, two families or even three. Then the household rates will not explain the availability of bed nets for usage.

Unlike households, we have found that Kenya ranked first place in owning bed nets per individual. This may be a result of the governmental efforts made in Kenya to distribute free ITNs to pregnant women and kids.[22] The lowest country was Uganda, however, more than half of the Ugandians sample reported holding bed nets. The difference between the percent of Uganda and Kenya is not significant enough to be justified.

For the usage rate, our meta-analysis proved that the Ethiopian households were the first ranking, while the Ugandians were the highest country in the level of individuals. Generally, the usage rate for both households and individuals were low compared to the possession rates. Some countries may show a high rate of usage due to the spread of the malarial concern, for example in Ethiopia $75 \%$ of its lands are a target for malarial infection.[120] While the respondents were not providing realistic answers well, this percentage may reflect a more accurate answer compared to the ownership rate. The lowest rates in net usage were for India and Yemen, which may be due to poverty and low socio-economic factors. Despite high rates for households, individuals may not find the cash to pay for nets purchasing per person. For Yemen, we can stem this rate to the instability and political/racial conflict that has existed for years there. [24] Several reasons also can work for this justification like using other tools for controlling malaria, 
favoring not to sleep under nets, allergy to insecticides or unavailability of a bed net $[40,121][40,121] .^{40}$, 121

Regarding the type of bed net used, the overall rate is in favour of the LLINs over the ITNs and un-treated nets. This may be attributed to the fact that LLIN is a breakthrough for the preventive measures of Malaria. While other insecticidal nets should be treated with insecticides at least once a year, this type of nets only need to be treated once while at the factory.[122] Another reason that may support the prevalence of LLINs is them being freely distributed or its economic costs, which is considered a low cost. Because of its efficacy, the national programs for controlling Malaria prefer using LLIN which can explain its spread.[123]

The low percentage of bed net usage is urging the medical organizations to push the awareness campaigns for humans across endemic areas to change their behavior towards bed nets. Also, there is a crucial need to enhance the programs that freely distribute bed nets.

Though our study included 106 articles, it possibly had several limitations. First, we used only search terms in English so we could miss studies in non-English articles. Second, most of the studies included were only from African and Asian countries that cannot present the whole global mapping. Third, there were only one or few studies in the subgroups resulting in a limitation of some pooled results. Four, the high heterogeneity could affect the strength of the evidence. Finally, it was not possible to analyze confounders that affect the pooled results.

\section{Conclusion}

Our study suggests that the bed net ownership and usage rates among different countries are not enough in several countries. While numerous factors are controlling the spread of bed nets globally, the proper intervention for preventive measures should include the study of human behaviors as well as the socioeconomic factors. Also, health organizations should work on improving awareness of preventive measures for this serious disease; to support the rural places and poor countries with the needed materials to stand against those diseases. For policymakers, we urge them to reconsider their regulations and plans for combating vector-borne diseases and to push social studies regularly as a tool to optimize their action plans for the betterment for their communities.

\section{Abbreviations}

ITNs=Insecticide-treated nets

LLINs=long lasting insecticides treated nets

$\mathrm{ND}=$ not determined

PRISMA= Preferred Reporting Items for Systematic Reviews and Meta-Analyses 


\section{Declarations}

\section{Ethics approval and consent to participate}

Not applicable

\section{Consent for publication}

Not applicable

\section{Availability of data and materials}

All data generated or analyzed during this study are included in this published article [and its supplementary information files].

\section{Funding}

None.

\section{Acknowledgement}

None.

\section{Competing interests}

Not declared.

\section{Authors' Contributions:}

MHM: She has participated in title and abstract screening, full text screening, data extraction, tables and figures, manuscript writing and final versions approval.

RLC: She has participated in title and abstract screening, full text screening, data extraction, manuscript writing and final versions approval.

GMT: She has participated in title and abstract screening, full text screening, data extraction, data analysis and its interpretation, tables and figures, manuscript writing and final versions approval.

AIR: She has participated in title and abstract screening, full text screening, data extraction, tables and figures, manuscript writing and final versions approval.

AES: He has participated in title and abstract screening, full text screening, data extraction, manuscript writing and final versions approval.

LJS: He has participated in title and abstract screening, full text screening, data extraction, manuscript writing and final versions approval. 
CGS: He has participated in title and abstract screening, full text screening, data extraction, manuscript writing and final versions approval.

AMS: He has participated in title and abstract screening, full text screening, data extraction, manuscript writing and final versions approval.

MAA: He has participated in title and abstract screening, full text screening, data extraction, manuscript writing and final versions approval.

BMA: She has participated in title and abstract screening, full text screening, data extraction, manuscript writing and final versions approval.

SMA: He has participated in title and abstract screening, full text screening, data extraction, manuscript writing and final versions approval.

FYA: She has participated in title and abstract screening, full text screening, data extraction, manuscript writing and final versions approval.

MME: He has participated in title and abstract screening, full text screening, data extraction, manuscript writing and final versions approval.

RHS: She has participated in title and abstract screening, full text screening, data extraction, manuscript writing and final versions approval.

HSM: She has participated in title and abstract screening, full text screening, data extraction, manuscript writing and final versions approval.

YMM: She has participated in title and abstract screening, full text screening, data extraction, manuscript writing and final versions approval.

AMK: He has participated in title and abstract screening, full text screening, data extraction, manuscript writing and final versions approval.

MIB: She has participated in title and abstract screening, full text screening, data extraction, manuscript writing and final versions approval.

AHA: He has participated in title and abstract screening, full text screening, data extraction, manuscript writing and final versions approval.

MAA: He has participated in title and abstract screening, full text screening, data extraction, manuscript writing and final versions approval.

AAA: He has participated in title and abstract screening, full text screening, data extraction, manuscript writing and final versions approval. 
MKA: He has participated in title and abstract screening, full text screening, data extraction, manuscript writing and final versions approval.

LLQ: He has participated in title and abstract screening, full text screening, data extraction, manuscript writing and final versions approval.

NDT: He has participated in title and abstract screening, full text screening, data extraction, manuscript writing and final versions approval.

MSD: He has participated in title and abstract screening, full text screening, data extraction, manuscript writing and final versions approval.

EMM: She has participated in title and abstract screening, full text screening, data extraction, manuscript writing and final versions approval.

SMS: He has participated in manuscript writing and final versions approval.

KM: He has participated in idea construction, manuscript writing and final versions approval.

NTH: He has participated in idea construction , supervision for all the PRISMA steps, manuscript writing and final versions approval.

\section{References}

1. Organization WH: Global technical strategy for malaria 2016-2030: World Health Organization; 2015.

2. Lathamani K, Kotigadde S: Prevelance of malaria and a comparative study of peripheral blood smear, quantitative buffy coat and malaria antigen rapid test methods in the diagnosis of malaria from Dakshina Kannada District. India 2013, 2(12):671-675.

3. Dabiré RK, Diabaté A, Baldet T, Paré-Toé L, Guiguemdé RT, Ouédraogo J-B, Skovmand O: Personal protection of long lasting insecticide-treated nets in areas of Anopheles gambiae ss resistance to pyrethroids. Malaria Journal 2006, 5(1):12.

4. Organization WH: World malaria report 2015: World Health Organization; 2016.

5. Lengeler C: Insecticide treated bednets and curtains for malaria control. Cochrane database of systematic reviews 1998(2).

6. Matthews G: Integrated vector management: controlling vectors of malaria and other insect vector borne diseases: John Wiley \& Sons; 2011.

7. Lengeler C: Insecticide-treated bed nets and curtains for preventing malaria. Cochrane Database of systematic reviews 2004(2):1-46.

8. Richardson M, Lengeler C, Pryce J: Insecticide-treated nets for preventing malaria. The Cochrane Database of Systematic Reviews 2018, 2018(11). 
9. Carnevale P, Gay F: Insecticide-Treated Mosquito Nets. In: Malaria Control and Elimination. edn.: Springer; 2019: 221-232.

10. Samadoulougou S, Pearcy M, Yé Y, Kirakoya-Samadoulougou F: Progress in coverage of bed net ownership and use in Burkina Faso 2003-2014: evidence from population-based surveys. Malaria journal 2017, 16(1):302.

11. Liberati A, Altman DG, Tetzlaff J, Mulrow C, Gøtzsche PC, loannidis JP, Clarke M, Devereaux PJ, Kleijnen J, Moher D: The PRISMA statement for reporting systematic reviews and meta-analyses of studies that evaluate health care interventions: explanation and elaboration. Annals of internal medicine 2009, 151(4):W-65-W-94.

12. Tawfik GM, Dila KAS, Mohamed MYF, Tam DNH, Kien ND, Ahmed AM, Huy NT: A step by step guide for conducting a systematic review and meta-analysis with simulation data. Tropical medicine and health 2019, 47:46.

13. 2013 Rwanda Malaria Indicator Survey (RMIS) Key Findings | medbox.org [https://www.medbox.org/rwanda/2013-rwanda-malaria-indicator-survey-rmis-key-findings/preview? $\mathrm{q}=$ files/362/preview.html]

14. Abeku TA, Helinski MEH, Kirby MJ, Kefyalew T, Awano T, Batisso E, Tesfaye G, Ssekitooleko J, Nicholas S, Erdmanis L: Monitoring changes in malaria epidemiology and effectiveness of interventions in Ethiopia and Uganda: Beyond Garki Project baseline survey. Malaria journal 2015, 14(1):337.

15. Adeniran AA, Mogaji OH, Oluwole SA, Abe ME, Bankole OS, Ekpo FU: Commodity utilization of malaria intervention and control tool: Access and utilization of long lasting insecticide net in rural communities of Imeko-Afon and Odeda local government area of Ogun state, Nigeria. Annals of Tropical Medicine and Public Health 2014, 7(2):85.

16. Adjah ESO, Panayiotou AG: Impact of malaria related messages on insecticide-treated net (ITN) use for malaria prevention in Ghana. Malaria journal 2014, 13(1):123.

17. Ahmed S, Galagan S, Scobie H, Khyang J, Prue CS, Khan WA, Ram M, Alam MS, Haq MZ, Akter J: Malaria hotspots drive hypoendemic transmission in the Chittagong Hill Districts of Bangladesh. PloS one 2013, 8(8):e69713.

18. Al-Adhroey AH, Nor ZM, Al-Mekhlafi HM, Mahmud R: Opportunities and obstacles to the elimination of malaria from Peninsular Malaysia: knowledge, attitudes and practices on malaria among aboriginal and rural communities. Malaria journal 2010, 9(1):137.

19. Aleme A, Girma E, Fentahun N: Willingness to pay for insecticide-treated nets in Berehet District, Amhara Region, Northern Ethiopia: implication of social marketing. Ethiopian journal of health sciences 2014, 24(1):75-84.

20. Andrada A, Herrera S, Inyang U, Mohammed AB, Uhomoibhi P, Yé Y: A subnational profiling analysis reveals regional differences as the main predictor of ITN ownership and use in Nigeria. Malaria journal 2019, 18(1):185. 
21. Ataka Y, Inaoka T, Ohtsuka R: Knowledge, attitudes and practices relevant to malaria control in remote island populations of Manus, Papua New Guinea. Tropical medicine and health 2011, 39(4):109-117.

22. Atieli HE, Zhou G, Afrane Y, Lee M-C, Mwanzo I, Githeko AK, Yan G: Insecticide-treated net (ITN) ownership, usage, and malaria transmission in the highlands of western Kenya. Parasites \& vectors 2011, 4(1):113.

23. Babalola S, Ricotta E, Awantang G, Lewicky N, Koenker H, Toso M: Correlates of intra-household ITN use in Liberia: a multilevel analysis of household survey data. PloS one 2016, 11(7).

24. Bamaga OA, Mahdy MA, Mahmud R, Lim YA: Malaria in Hadhramout, a southeast province of Yemen: prevalence, risk factors, knowledge, attitude and practices (KAPs). Parasites \& vectors 2014, 7(1):351.

25. Berhane A, Mihreteab S, Ahmed H, Zehaie A, Abdulmumini $U$, Chanda E: Gains attained in malaria control coverage within settings earmarked for preelimination: malaria indicator and prevalence surveys 2012, Eritrea. Malaria journal 2015, 14(1):467.

26. Bernard J, Mtove G, Mandike R, Mtei F, Maxwell C, Reyburn H: Equity and coverage of insecticidetreated bed nets in an area of intense transmission of Plasmodium falciparum in Tanzania. Malaria Journal 2009, 8(1):65.

27. Biadgilign S, Reda A, Kedir H: Determinants of ownership and utilization of insecticide-treated bed nets for malaria control in eastern Ethiopia. Journal of tropical medicine 2012, 2012.

28. Birhanu Z, Abebe L, Sudhakar M, Dissanayake G, Yihdego Y, Alemayehu G, Yewhalaw D: Access to and use gaps of insecticide-treated nets among communities in Jimma Zone, southwestern Ethiopia: baseline results from malaria education interventions. BMC Public Health 2015, 15(1):1304.

29. Boakye DA, Adasi K, Appawu M, Brown CA, Wilson MD: Patterns of household insecticide use and pyrethroid resistance in Anopheles gambiae sensu stricto (Diptera: Culicidae) within the Accra metropolis of Ghana. African Entomology 2009, 17(2):125-131.

30. Boulay M, Lynch M, Koenker H: Comparing two approaches for estimating the causal effect of behaviour-change communication messages promoting insecticide-treated bed nets: an analysis of the 2010 Zambia malaria indicator survey. Malaria journal 2014, 13(1):342.

31. Bowen HL: Impact of a mass media campaign on bed net use in Cameroon. Malaria journa/2013, 12(1):36.

32. Brant TA, Okorie PN, Ogunmola O, Ojeyode NB, Fatunade S, Davies E, Saka Y, Stanton MC, Molyneux $\mathrm{DH}$, Stothard JR: Integrated risk mapping and landscape characterisation of lymphatic filariasis and loiasis in South West Nigeria. Parasite epidemiology and control 2018, 3(1):21-35.

33. Brooks HM, Paul MKJ, Claude KM, Mocanu V, Hawkes MT: Use and disuse of malaria bed nets in an internally displaced persons camp in the Democratic Republic of the Congo: a mixed-methods study. PloS one 2017, 12(9):e0185290.

34. Buchwald AG, Coalson JE, Cohee LM, Walldorf JA, Chimbiya N, Bauleni A, Nkanaunena K, Ngwira A, Sorkin JD, Mathanga DP: Insecticide-treated net effectiveness at preventing Plasmodium falciparum 
infection varies by age and season. Malaria journal 2017, 16(1):32.

35. Burgert CR, Bradley SE, Arnold F, Eckert E: Improving estimates of insecticide-treated mosquito net coverage from household surveys: using geographic coordinates to account for endemicity. Malaria journal 2014, 13(1):254.

36. Ce $\mathrm{O}, \mathrm{Cb} D, \mathrm{Ns} A$, So $\mathrm{A}$, Fo E, C A, A N: Awareness, ownership and utilization of insecticide treated nets in Abavo community of Delta State. Niger J Med 2013, 22(4):326-331.

37. Chinwe E: Patterns of Plasmodium falciparum among Settled Fulani Pastoralists in Rivers State, Nigeria. IJTDH 2014, 4(3):295-305.

38. Dawaki S, Al-Mekhlafi HM, Ithoi I, Ibrahim J, Atroosh WM, Abdulsalam AM, Sady H, Elyana FN, Adamu AU, Yelwa SI: Is Nigeria winning the battle against malaria? Prevalence, risk factors and KAP assessment among Hausa communities in Kano State. Malaria journal 2016, 15(1):351.

39. Debo GW, Kassa DH: Prevalence of malaria and associated factors in Benna Tsemay district of pastoralist community, Southern Ethiopia. Tropical diseases, travel medicine and vaccines 2016, 2:16.

40. Deressa W, Hailemariam D, Ali A: Economic costs of epidemic malaria to households in rural Ethiopia. Tropical Medicine \& International Health 2007, 12(10):1148-1156.

41. Egbuche C, Eneanya C, Aribodor D, Eneanya O, Ogbuagu C, Ezugbo-Nwobi I: Malaria Prevalence and Use of Insecticide-Treated Net among Community Members in Aguleri, Anambra State, Nigeria. The Bioscientist 2013, 1(1):60-66.

42. Elder JP, Botwe AA, Selby RA, Franklin N, Shaw WD: Community trial of insecticide-treated bed net use promotion in southern Ghana: the Net Use Intervention study. Translational behavioral medicine 2011, 1(2):341-349.

43. Escamilla V, Alker A, Dandalo L, Juliano JJ, Miller WC, Kamthuza P, Tembo T, Tegha G, Martinson F, Emch $\mathrm{M}$ et al: Effects of community-level bed net coverage on malaria morbidity in Lilongwe, Malawi. Malaria Journal 2017, 16(1):142.

44. Ezeigbo O, Ejike E, Nwachukwu I: Insecticide-Treated Bed Net (ITN): Ownership and Usage in the Control of Malaria in Abia State, Nigeria. American Journal of Epidemiology and Infectious Disease 2016, 4(3):42-46.

45. Gari T, Kenea O, Loha E, Deressa W, Hailu A, Balkew M, Gebre-Michael T, Robberstad B, Overgaard HJ, Lindtjørn B: Malaria incidence and entomological findings in an area targeted for a clusterrandomized controlled trial to prevent malaria in Ethiopia: results from a pilot study. Malaria Journal 2016, 15(1):145.

46. Gobena T, Berhane Y, Worku A: Low long-lasting insecticide nets (LLINs) use among household members for protection against mosquito bite in kersa, Eastern Ethiopia. BMC public health 2012, 12(1):914.

47. Gonahasa S, Maiteki-Sebuguzi C, Rugnao S, Dorsey G, Opigo J, Yeka A, Katureebe A, Kyohere M, Lynd A, Hemingway J: LLIN Evaluation in Uganda Project (LLINEUP): factors associated with ownership 
and use of long-lasting insecticidal nets in Uganda: a cross-sectional survey of $\mathbf{4 8}$ districts. Malaria journal 2018, 17(1):421.

48. Gryseels C, Peeters Grietens K, Dierickx S, Xuan XN, Uk S, Bannister-Tyrrell M, Trienekens S, Ribera JM, Hausmann-Muela S, Gerrets R et al: High Mobility and Low Use of Malaria Preventive Measures Among the Jarai Male Youth Along the Cambodia-Vietnam Border. The American journal of tropical medicine and hygiene 2015, 93(4):810-818.

49. Hailu A, Lindtjørn B, Deressa W, Gari T, Loha E, Robberstad B: Equity in long-lasting insecticidal nets and indoor residual spraying for malaria prevention in a rural South Central Ethiopia. Malaria Journal 2016, 15(1):366.

50. Hambisa MT, Debela T, Dessie Y, Gobena T: Long lasting insecticidal net use and its associated factors in Limmu Seka District, South West Ethiopia. BMC Public Health 2018, 18(1):124.

51. Hanafi-Bojd A, Vatandoost H, Oshaghi M, Eshraghian M, Haghdoost A, Abedi F, Zamani G, Sedaghat $M$, Rashidian A, Madani $A$ : Knowledge, attitudes and practices regarding malaria control in an endemic area of southern Iran. Southeast Asian Journal of Tropical Medicine and Public Health 2011, 42(3):491-501.

52. Haque U, Hashizume M, Sunahara T, Hossain S, Ahmed SM, Haque R, Yamamoto T, Glass GE: Progress and challenges to control malaria in a remote area of Chittagong hill tracts, Bangladesh. Malaria Journal 2010, 9(1):156.

53. Hetzel MW, Gideon G, Lote N, Makita L, Siba PM, Mueller I: Ownership and usage of mosquito nets after four years of large-scale free distribution in Papua New Guinea. Malaria journal 2012, 11(1):192.

54. Homan T, di Pasquale A, Onoka K, Kiche I, Hiscox A, Mweresa C, Mukabana WR, Masiga D, Takken W, Maire N: Profile: the Rusinga health and demographic surveillance system, western Kenya. International journal of epidemiology 2016, 45(3):718-727.

55. Iliyasu Z, Umar A, Aminu G, Jahun S: Perception and predictors of insecticide-treated net use in a rural Northern Nigerian community. Sahel Medical Journal 2010, 13(4).

56. Kaliyaperumal K, Yesuf D: Knowledge, attitudes and practices of local inhabitants about insecticide treated nets (ITNs) for malaria control in an endemic area of Ethiopia. East Afr J Public Health 2009, 6(2):206-2011.

57. Kateera F, Ingabire CM, Hakizimana E, Rulisa A, Karinda P, Grobusch MP, Mutesa L, van Vugt M, Mens PF: Long-lasting insecticidal net source, ownership and use in the context of universal coverage: a household survey in eastern Rwanda. Malaria journal 2015, 14(1):390.

58. Kateera F, Mens PF, Hakizimana E, Ingabire CM, Muragijemariya L, Karinda P, Grobusch MP, Mutesa L, van Vugt M: Malaria parasite carriage and risk determinants in a rural population: a malariometric survey in Rwanda. Malaria journal 2015, 14(1):16.

59. Kesteman T, Rafalimanantsoa SA, Razafimandimby H, Rasamimanana HH, Raharimanga V, Ramarosandratana B, Ratsimbasoa A, Ratovonjato J, Elissa N, Randrianasolo L: Multiple causes of 
an unexpected malaria outbreak in a high-transmission area in Madagascar. Malaria journa/2016, 15(1):57.

60. Kesteman T, Randrianarivelojosia M, Mattern C, Raboanary E, Pourette D, Girond F, Raharimanga V, Randrianasolo L, Piola P, Rogier C: Nationwide evaluation of malaria infections, morbidity, mortality, and coverage of malaria control interventions in Madagascar. Malaria journal 2014, 13(1):465.

61. Khairy S, Al-Surimi K, Ali A, Shubily HM, Al Walaan N, Househ M, El-Metwally A: Knowledge, attitude and practice about malaria in south-western Saudi Arabia: a household-based cross-sectional survey. Journal of infection and public health 2017, 10(5):499-506.

62. Khatib RA, Chaki PP, Wang D-Q, Mlacha YP, Mihayo MG, Gavana T, Xiao N, Zhou X-N, Abdullah S: Epidemiological characterization of malaria in rural southern Tanzania following China-Tanzania pilot joint malaria control baseline survey. Malaria journal 2018, 17(1):292.

63. Kilian A, Koenker H, Baba E, Onyefunafoa EO, Selby RA, Lokko K, Lynch M: Universal coverage with insecticide-treated nets-applying the revised indicators for ownership and use to the Nigeria $\mathbf{2 0 1 0}$ malaria indicator survey data. Malaria journal 2013, 12(1):314.

64. Kirkby K, Galappaththy GN, Kurinczuk JJ, Rajapakse S, Fernando SD: Knowledge, attitudes and practices relevant to malaria elimination amongst resettled populations in a post-conflict district of northern Sri Lanka. Transactions of The Royal Society of Tropical Medicine and Hygiene 2012, 107(2):110-118.

65. Kitidamrongsuk P, Jareinpituk S, Pattanasin S, Viwatwongkasem C, Soontornpipit P, Silabutra J, Satitvipawee P: Determinants of Impregnated Net Ownership and Utilization in Rural Community on the Thai-Myanmar Border in Prachuab Khiri Khan, Thailand. Procedia Computer Science 2016, 86:224-227.

66. Kohli C, Kumar R, Meena GS, Singh MM, Sahoo J, Ingle GK: Usage and perceived side effects of personal protective measures against mosquitoes among current users in Delhi. Journal of parasitology research 2014, 2014.

67. Kudom AA, Mensah BA, Nunoo J: Assessment of anti mosquito measures in households and resistance status of Culex species in urban areas in southern Ghana: Implications for the sustainability of ITN use. Asian Pacific journal of tropical medicine 2013, 6(11):859-864.

68. Larson PS, Minakawa N, Dida GO, Njenga SM, lonides EL, Wilson ML: Insecticide-treated net use before and after mass distribution in a fishing community along Lake Victoria, Kenya: successes and unavoidable pitfalls. Malaria journal 2014, 13(1):466.

69. Liu H, Xu J-w, Guo X-r, Havumaki J, Lin Y-x, Yu G-c, Zhou D-I: Coverage, use and maintenance of bed nets and related influence factors in Kachin Special Region II, northeastern Myanmar. Malaria journal 2015, 14(1):212.

70. Liverani M, Charlwood JD, Lawford H, Yeung S: Field assessment of a novel spatial repellent for malaria control: a feasibility and acceptability study in Mondulkiri, Cambodia. Malaria Journa/2017, 16(1):412. 
71. Loha E, Tefera K, Lindtjørn B: Freely distributed bed-net use among Chano Mille residents, south Ethiopia: a longitudinal study. Malaria Journal 2013, 12(1):23.

72. Masangwi S, Grimason A, Morse T, Ferguson N, Kazembe L: Community knowledge variation, bed-net coverage and the role of a district healthcare system, and their implications for malaria control in southern Malawi. Southern African Journal of Epidemiology and Infection 2012, 27(3):116-125.

73. Maung TM, Oo T, Wai KT, Hlaing T, Owiti P, Kumar B, Shewade HD, Zachariah R, Thi A: Assessment of household ownership of bed nets in areas with and without artemisinin resistance containment measures in Myanmar. Infectious diseases of poverty 2018, 7(1):19.

74. Maung TM, Tripathy JP, Oo T, Oo SM, Soe TN, Thi A, Wai KT: Household ownership and utilization of insecticide-treated nets under the Regional Artemisinin Resistance Initiative in Myanmar. Tropical medicine and health 2018, 46(1):27.

75. Mazigo HD, Obasy E, Mauka W, Manyiri P, Zinga M, Kweka EJ, Mnyone LL, Heukelbach J: Knowledge, attitudes, and practices about malaria and its control in rural northwest Tanzania. Malaria Research and Treatment 2010, 2010.

76. Moon TD, Hayes CB, Blevins M, Lopez ML, Green AF, González-Calvo L, Olupona O: Factors associated with the use of mosquito bed nets: results from two cross-sectional household surveys in Zambézia Province, Mozambique. Malaria journa/2016, 15(1):196.

77. Muchie KF, Alemu K, Tariku A, Tsegaye AT, Abebe SM, Yitayal M, Awoke T, Biks GA: Rural households at risk of malaria did not own sufficient insecticide treated nets at Dabat HDSS site: evidence from a cross sectional re-census. BMC Public Health 2017, 17(1):888.

78. Mukhopadhyay DK, Basu SS, Roy D, Das NG, Akbar F, Sarkar GN: Netting the malaria menace: Distribution and utilization of long-lasting insecticidal net in a malaria endemic area in Bankura, West Bengal. Journal of vector borne diseases 2016, 53(1):23-29.

79. Nchang CF, Cho-Azieh NFP, Fri MS, Menyi CB, Kofon JP, Tassang NFC, Peter NF, Andrew N T: 2018.

80. Negash $K$, Haileselassie B, Tasew A, Ahmed Y, Getachew M: Ownership and utilization of long-lasting insecticide-treated bed nets in Afar, northeast Ethiopia: a cross-sectional study. The Pan African Medical Journal 2012, 13(Suppl 1).

81. Ntuku HM, Ruckstuhl L, Julo-Réminiac J-E, Umesumbu SE, Bokota A, Tshefu AK, Lengeler C: Longlasting insecticidal net (LLIN) ownership, use and cost of implementation after a mass distribution campaign in Kasaï Occidental Province, Democratic Republic of Congo. Malaria journal 2017, 16(1):22.

82. Odoemene N, Adeniran A, Oluwole A, Mogaji H, Abe E, Sam-Wobo S, Agboola O, Ekpo U: Communal prevalence of malaria parasite and evaluation of Long Lasting Insecticidal Treated Nets (LLINs) for malaria control in Ikenne, Ogun State, Nigeria. Nigerian Journal of Parasitoogy, 38 [1] 2017:57-64.

83. Osuorah DC, Ezeudu CE, Onah SK, Anyabolu OT: Household bed net ownership and use among under-5 children in Nigeria. Research and reports in tropical medicine 2013, 4:15.

84. Pongvongsa T, Ha H, Thanh L, Marchand RP, Nonaka D, Tojo B, Phongmany P, Moji K, Kobayashi J: Joint malaria surveys lead towards improved cross-border cooperation between Savannakhet 
province, Laos and Quang Tri province, Vietnam. Malaria journal 2012, 11(1):262.

85. Ricotta E, Oppong S, Yukich JO, Briët OJT: Determinants of bed net use conditional on access in population surveys in Ghana. Malaria Journal 2019, 18(1):63.

86. Ruberto I, Camara S, Banek K, Loua MK: Knowledge, attitudes and practices of malaria control among communities from the health district of Forécariah in the Republic of Guinea, West Africa. Journal of vector borne diseases 2014, 51(2):119.

87. Scott CA, Yeshiwondim AK, Serda B, Guinovart C, Tesfay BH, Agmas A, Zeleke MT, Guesses GS, Ayenew AL, Workie WM: Mass testing and treatment for malaria in low transmission areas in Amhara Region, Ethiopia. Malaria journal 2016, 15(1):305.

88. Sena LD, Deressa WA, Ali AA: Predictors of long-lasting insecticide-treated bed net ownership and utilization: evidence from community-based cross-sectional comparative study, Southwest Ethiopia. Malaria journal 2013, 12(1):406.

89. Seyoum D, Speybroeck N, Duchateau L, Brandt P, Rosas-Aguirre A: Long-lasting insecticide net ownership, access and use in southwest Ethiopia: A community-based cross-sectional study. International journal of environmental research and public health 2017, 14(11):1312.

90. Skarbinski J, Mwandama D, Luka M, Jafali J, Wolkon A, Townes D, Campbell C, Zoya J, Ali D, Mathanga DP: Impact of health facility-based insecticide treated bednet distribution in Malawi: progress and challenges towards achieving universal coverage. PLOS One 2011, 6(7):e21995.

91. Ssempiira J, Nambuusi B, Kissa J, Agaba B, Makumbi F, Kasasa S, Vounatsou P: The contribution of malaria control interventions on spatio-temporal changes of parasitaemia risk in Uganda during 2009-2014. Parasites \& vectors 2017, 10(1):450.

92. Stephenson CJ, Rossheim ME, Frankenfeld CL, Boncy J, Okech BA, von Fricken ME: Cross-sectional analysis of the association between bedtime and malaria exposure in the Ouest and Sud-Est Departments of Haiti. Acta tropica 2017, 176:188-191.

93. Stevenson JC, Stresman GH, Baidjoe A, Okoth A, Oriango R, Owaga C, Marube E, Bousema T, Cox J, Drakeley $\mathrm{C}$ : Use of different transmission metrics to describe malaria epidemiology in the highlands of western Kenya. Malaria journal 2015, 14(1):418.

94. Tadele G, Samuel A, Adeba E: Replacement of long lasting insecticide treated nets in malarious kebeles of Gida Ayana district, East Wollega zone, Ethiopia. Science, Technology and Arts Research Journal 2014, 3(2):162-166.

95. Tarimo DS: Community knowledge and perceived effectiveness of interventions to reduce malaria: implications for sustained use of malaria interventions in Rufiji district, Southeastern Tanzania. International quarterly of community health education 2015, 35(4):335-347.

96. Tassew A, Hopkins R, Deressa W: Factors influencing the ownership and utilization of long-lasting insecticidal nets for malaria prevention in Ethiopia. Malaria journal 2017, 16(1):262.

97. Tchinda VHM, Socpa A, Keundo AA, Zeukeng F, Seumen CT, Leke RGF, Moyou RS: Factors associated to bed net use in Cameroon: a retrospective study in Mfou health district in the Centre Region. Pan African Medical Journal 2012, 12(1). 
98. Teklemariam Z, Awoke A, Dessie Y, Weldegebreal F: Ownership and utilization of insecticide-treated nets (ITNs) for malaria control in Harari National Regional State, Eastern Ethiopia. Pan African Medical Journal 2015, 21(1).

99. Tiffany A, Moundekeno FP, Traoré A, Haile M, Sterk E, Guilavogui T, Genton B, Serafini M, Grais RF: Encouraging impact following 2.5 years of reinforced malaria control interventions in a hyperendemic region of the Republic of Guinea. Malaria journa/2016, 15(1):298.

100. Tobin-West C, Alex-Hart B: Insecticide-treated bednet ownership and utilization in Rivers State, Nigeria before a state-wide net distribution campaign. Journal of vector borne diseases 2011, 48(3):133.

101. Tomass Z, Alemayehu B, Balkew M, Leja D: Knowledge, attitudes and practice of communities of Wolaita, Southern Ethiopia about long-lasting insecticidal nets and evaluation of net fabric integrity and insecticidal activity. Parasites \& vectors 2016, 9(1):224.

102. Tomass Z, Dejene T, Kidane D: Knowledge, attitude and practice (KAP) about insecticide treated net (ITN) usage against malaria in Kolla Tembien district, Tigray, Ethiopia. Momona Ethiopian Journal of Science $2011,3(2)$.

103. Vala MC, Patel UV, Joshi NB, Zalavadiya DD, Viramgami AP, Sharma S: Knowledge and practice regarding malaria among people of urban and rural areas of Rajkot District, Gujarat. India. Int $J$ Res Med 2013, 2(4):38-42.

104. van Eijk AM, Ramanathapuram L, Sutton PL, Peddy N, Choubey S, Mohanty S, Asokan A, Ravishankaran S, Priya GS, Johnson JA et al: The use of mosquito repellents at three sites in India with declining malaria transmission: surveys in the community and clinic. Parasit Vectors 2016, $9(1): 418$.

105. Vitor-Silva S, Siqueira AM, de Souza Sampaio V, Guinovart C, Reyes-Lecca RC, de Melo GC, Monteiro WM, Del Portillo HA, Alonso P, Bassat Q: Declining malaria transmission in rural Amazon: changing epidemiology and challenges to achieve elimination. Malaria journal 2016, 15(1):266.

106. Walldorf JA, Cohee LM, Coalson JE, Bauleni A, Nkanaunena K, Kapito-Tembo A, Seydel KB, Ali D, Mathanga D, Taylor TE: School-age children are a reservoir of malaria infection in Malawi. PloS one 2015, 10(7):e0134061.

107. Wang R-b, Zhang J, Zhang Q-f: Malaria baseline survey in four special regions of northern Myanmar near China: a cross-sectional study. Malaria Journal 2014, 13(1):302.

108. Wanzira H, Eganyu T, Mulebeke R, Bukenya F, Echodu D, Adoke Y: Long lasting insecticidal bed nets ownership, access and use in a high malaria transmission setting before and after a mass distribution campaign in Uganda. PloS one 2018, 13(1):e0191191.

109. Watanabe N, Kaneko A, Yamar S, Leodoro H, Taleo G, Tanihata T, Lum JK, Larson PS: Determinants of the use of insecticide-treated bed nets on islands of pre- and post-malaria elimination: an application of the health belief model in Vanuatu. Malaria Journal 2014, 13(1):441.

110. Watiro AH, Awoke W: Insecticide-treated net ownership and utilization and factors that influence their use in Itang, Gambella region, Ethiopia: cross-sectional study. Risk management and healthcare policy 2016, 9:101. 
111. West PA, Protopopoff N, Rowland MW, Kirby MJ, Oxborough RM, Mosha FW, Malima R, Kleinschmidt I: Evaluation of a national universal coverage campaign of long-lasting insecticidal nets in a rural district in north-west Tanzania. Malaria journal 2012, 11(1):273.

112. Widmar M, Nagel CJ, Ho DY, Benziger PW, Hennig N: Determining and addressing obstacles to the effective use of long-lasting insecticide-impregnated nets in rural Tanzania. Malaria journa/ 2009, 8(1):315.

113. Woyessa A, Deressa W, Ali A, Lindtjørn B: Ownership and use of long-lasting insecticidal nets for malaria prevention in Butajira area, south-central Ethiopia: complex samples data analysis. $B M C$ Public Health 2014, 14(1):99.

114. Xu J-w, Liao Y-m, Liu H, Nie R-h, Havumaki J: Use of bed nets and factors that influence bed net use among Jinuo Ethnic Minority in southern China. PLoS One 2014, 9(7):e103780.

115. Ye Y, Patton E, Kilian A, Dovey S, Eckert E: Can universal insecticide-treated net campaigns achieve equity in coverage and use? The case of northern Nigeria. Malaria journal 2012, 11(1):32.

116. Zhao Y, Zeng J, Zhao Y, Liu Q, He Y, Zhang J, Yang Z, Fan Q, Wang Q, Cui L: Risk factors for asymptomatic malaria infections from seasonal cross-sectional surveys along the China-Myanmar border. Malaria journal 2018, 17(1):247.

117. Eng JLV, Thwing J, Wolkon A, Kulkarni MA, Manya A, Erskine M, Hightower A, Slutsker L: Assessing bed net use and non-use after long-lasting insecticidal net distribution: a simple framework to guide programmatic strategies. Malaria journal 2010, 9(1):133.

118. Heggenhougen HK, Hackethal V, Vivek P: The behavioural and social aspects of malaria and its control: an introduction and annotated biliography. In.: Geneva:: World Health Organization; 2003.

119. Bashwari L, Mandil AM, Bahnassy AA, Al-Shamsi MA, Bukhari HA: Epidemiological profile of malaria in a university hospital in the eastern region of Saudi Arabia. Saudi medical journal 2001, 22(2):133138.

120. Alelign A, Dejene T: Current status of malaria in Ethiopia: evaluation of the burden, factors for transmission and prevention methods. Acta Parasitol Glob 2016, 7:1-6.

121. Dicko A, Diallo Al, Tembine I, Dicko Y, Dara N, Sidibe Y, Santara G, Diawara H, Conaré T, Djimde A: Intermittent preventive treatment of malaria provides substantial protection against malaria in children already protected by an insecticide-treated bednet in Mali: a randomised, double-blind, placebo-controlled trial. PLoS medicine 2011, 8(2).

122. Guillet P, Alnwick D, Cham MK, Neira M, Zaim M, Heymann D, Mukelabai K: Long-lasting treated mosquito nets: a breakthrough in malaria prevention. Bulletin of the World Health Organization 2001, 79.

123. Atkinson J-A, Bobogare A, Fitzgerald L, Boaz L, Appleyard B, Toaliu H, Vallely A: A qualitative study on the acceptability and preference of three types of long-lasting insecticide-treated bed nets in Solomon Islands: implications for malaria elimination. Malaria journal 2009, 8(1):119.

\section{Supplementary Data}


Supplementary Table 1. PRISMA checklist.

Supplementary Table 2. Details of search terms in each database.

Supplementary Table 3. Characteristics of included studies.

Supplementary Figure 1. Global mapping of household ownership rate.

Supplementary Figure 2. Meta-analysis for bed net household owner: subgroup for bed net used.

Supplementary Figure 3. Meta-analysis for bed net individual owner: subgroup for bed net used.

Supplementary Figure 4. Global mapping of household usage rate of bed net. Supplementary Figure 5. Meta-analysis for bed net individual owner rate: subgroup bed net used.

Supplementary Figure 6. Meta-analysis for bed net individual usage rate: subgroup bed net used.

Supplementary Figure 7. Funnel plot of standard error demonstrating publication bias.

\section{Figures}

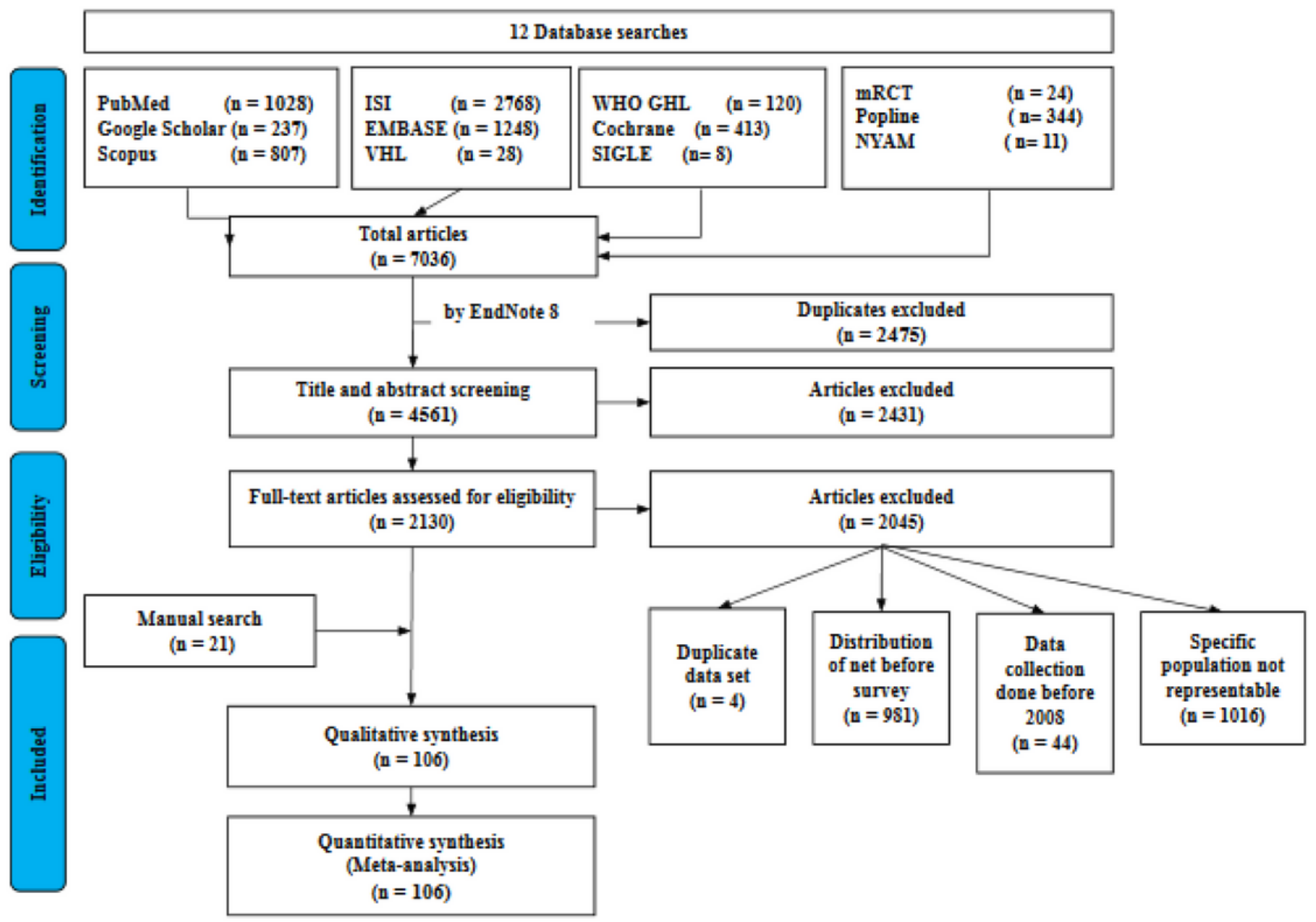


Figure 1

PRISMA flow diagram of study selection. PRISMA flow diagram reveals 106 studies included in our metaanalysis. Electronic search 12 different databases showed a total of 7036 results. After title, abstract and full text screening, a total of 85 studies were eligible. Further 21 studies were added after manual search.

\section{Meta-analy sis for house hold owner rate: subgroup for countries}

\begin{tabular}{lcccc} 
Group by & \multicolumn{3}{c}{ Events/Total } \\
\cline { 1 - 4 } Country & $\begin{array}{c}\text { Event } \\
\text { rate }\end{array}$ & $\begin{array}{c}\text { Lower } \\
\text { limit }\end{array}$ & $\begin{array}{c}\text { Upper } \\
\text { limit }\end{array}$ & Tolal \\
Bangladesh & 0.984 & 0.894 & 0.998 & $5236 / 5322$ \\
Burkina Faso & 0.774 & 0.460 & 0.932 & $14004 / 20872$ \\
Burundi & 0.520 & 0.131 & 0.886 & $4470 / 8596$ \\
Cambodia & 0.954 & 0.695 & 0.995 & $83 / 87$ \\
Cameroon & 0.743 & 0.480 & 0.900 & $2947 / 4358$ \\
China & 0.446 & 0.165 & 0.765 & $314 / 704$ \\
Congo & 0.342 & 0.112 & 0.680 & $230 / 609$ \\
Eritrea & 0.900 & 0.555 & 0.985 & $1636 / 1818$ \\
Ethiopia & 0.680 & 0.586 & 0.761 & $13906 / 27399$ \\
Ghana & 0.591 & 0.375 & 0.778 & $20404 / 32755$ \\
Guinea & 0.650 & 0.371 & 0.854 & $434 / 662$ \\
India & 0.818 & 0.384 & 0.970 & $1063 / 1300$ \\
Keny a & 0.647 & 0.313 & 0.881 & $9861 / 15673$ \\
Liberia & 0.360 & 0.073 & 0.802 & $432 / 1200$ \\
Madagascar & 0.640 & 0.199 & 0.927 & $2286 / 3572$ \\
Malawi & 0.699 & 0.464 & 0.862 & $7218 / 10629$ \\
Mozambique & 0.640 & 0.198 & 0.927 & $2399 / 3749$ \\
My anmar & 0.736 & 0.536 & 0.871 & $12595 / 16460$ \\
New Guinea & 0.525 & 0.133 & 0.889 & $313 / 596$ \\
Nigeria & 0.521 & 0.375 & 0.664 & $12681 / 24042$ \\
Rwanda & 0.883 & 0.738 & 0.953 & $19242 / 22685$ \\
Saudi Arabia & 0.221 & 0.037 & 0.675 & $57 / 258$ \\
Sengal & 0.630 & 0.192 & 0.924 & $4902 / 7780$ \\
Sri Lanka & 0.940 & 0.674 & 0.992 & $282 / 300$ \\
Tanzania & 0.885 & 0.785 & 0.942 & $17088 / 19727$ \\
Thailand & 0.750 & 0.424 & 0.924 & $909 / 1356$ \\
Uganda & 0.776 & 0.563 & 0.903 & $7730 / 10809$ \\
Vietnam & 0.956 & 0.838 & 0.989 & $1002 / 1046$ \\
Zambia & 0.700 & 0.245 & 0.944 & $2150 / 3071$ \\
Zimbabwe & 0.053 & 0.741 & $2689 / 9442$ \\
Ov erall & 0.629 & 0.797 & $168563 / 256877$
\end{tabular}
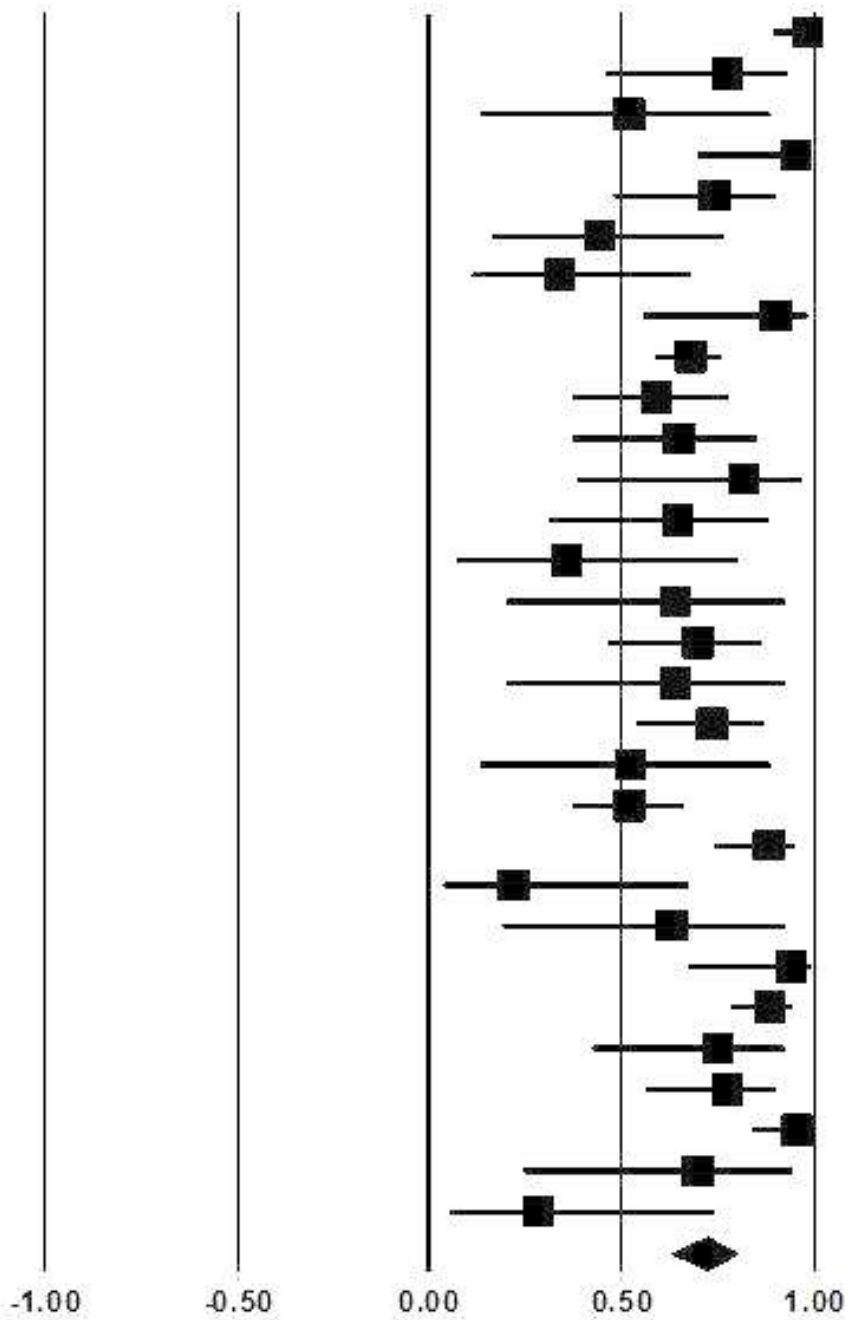

Figure 2

Meta-analysis for bed net household owner: subgroup for countries. This figure shows meta-analysis of ownership rate among different countries per household study unit. The analysis proved that Bangladesh has the highest prevalence of ownership regarding household bednets and on contrast Saudi Arabia has the lowest ownership. The overall ownership rate (event rate=72.1\%, 95\% Cl: 62.9-79.7). 


\section{Meta-analy sis for individual owner rate: subgroup for countries}

$\begin{array}{lcccc}\begin{array}{l}\text { Group by } \\ \text { Country }\end{array} & \begin{array}{c}\text { Event } \\ \text { rate }\end{array} & \begin{array}{c}\text { Lower } \\ \text { limit }\end{array} & \begin{array}{c}\text { Upper } \\ \text { limit }\end{array} & \text { Total } \\ \text { Ethiopia } & 0.672 & 0.584 & 0.749 & 30100 / 44938 \\ \text { Guinea } & 0.400 & 0.281 & 0.532 & 2779 / 6947 \\ \text { Haiti } & 0.682 & 0.547 & 0.792 & 257 / 377 \\ \text { Kenya } & 0.729 & 0.647 & 0.799 & 1767 / 2425 \\ \text { Liberia } & 0.351 & 0.241 & 0.480 & 2269 / 6463 \\ \text { Nigeria } & 0.685 & 0.620 & 0.744 & 1494 / 2057 \\ \text { IJganda } & 0.147 & 00.92 & 0228 & 4.369 / 29627 \\ \text { Vietnam } & 0.553 & 0.410 & 0.688 & 166 / 300 \\ \text { Overall } & 0.525 & 0.370 & 0.674 & 43201 / 93134\end{array}$

Event rate and $95 \% \mathrm{Cl}$

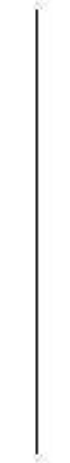

$-1.00$

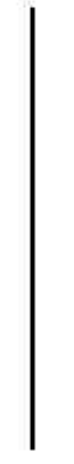

$-0.50$

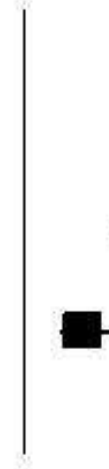

0.00

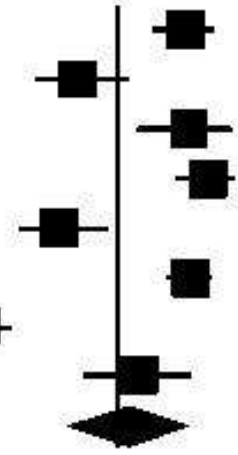

0.50

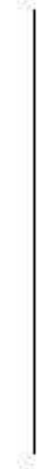

1.00

Figure 3

Meta-analysis for bed net individual owner: subgroup for countries. The figure shows the results of metaanalysis of bed net ownership among different countries per individual unit. As regards ownership rate, Kenya is considered the highest country, but Uganda is the lowest. The overall rate is $52.5 \%$ (95\% Cl: $37.0-$ 67.4)

\section{Meta-analy sis for household usage rate: subgroup for countries}

\begin{tabular}{lcccc} 
Group by & \multicolumn{5}{c}{ Country } & $\begin{array}{c}\text { Event } \\
\text { rate }\end{array}$ & $\begin{array}{c}\text { Lower } \\
\text { limit }\end{array}$ & $\begin{array}{c}\text { Upper } \\
\text { limit }\end{array}$ & Total \\
Cameroon & 0.247 & 0.078 & 0.559 & $1013 / 3817$ \\
Ehiopia & 0.548 & 0.411 & 0.678 & $5596 / 11076$ \\
Ghana & 0.059 & 0.008 & 0.319 & $10 / 170$ \\
Guinea & 0.495 & 0.125 & 0.871 & $99 / 200$ \\
India & 0.193 & 0.073 & 0.419 & $1475 / 9291$ \\
Iran & 0.595 & 0.178 & 0.909 & $294 / 494$ \\
Malaysia & 0.623 & 0.194 & 0.919 & $139 / 223$ \\
Mozambique & 0.370 & 0.080 & 0.798 & $1386 / 3749$ \\
Nigeria & 0.387 & 0.194 & 0.623 & $468 / 1359$ \\
Saudi Arabia & 0.155 & 0.026 & 0.560 & $40 / 258$ \\
Tanzania & 0.740 & 0.294 & 0.951 & $271 / 366$ \\
Uganda & 0.568 & 0.163 & 0.899 & $1731 / 3045$ \\
Vetnam & 0.903 & 0.703 & 0.973 & $945 / 1046$ \\
Yemen & 0.108 & 0.016 & 0.468 & $14 / 130$ \\
Overall & 0.412 & 0.251 & 0.593 & $13481 / 35224$
\end{tabular}

Event rate and $95 \% \mathrm{Cl}$

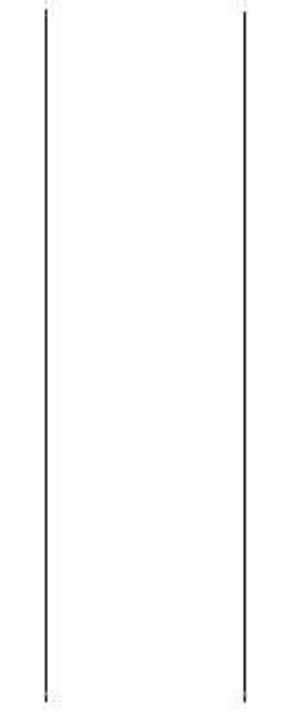

$-1.00$
$-0.50$

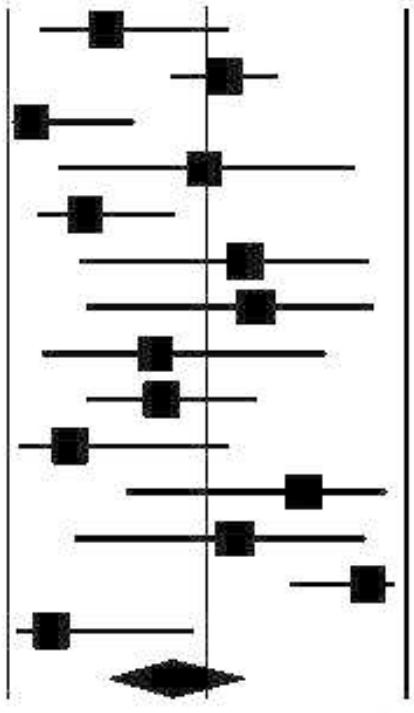

0.00

0.50

1.00

Figure 4 
Meta-analysis for bed net household usage rate: subgroup for countries. The analysis reveals Vietnam recorded the highest prevalence of household bednet usage all over the world on contrast the lowest is Ghana. Unfortunately, the usage rate is very low comparing to the ownership rate.

\section{Meta-analysis for individual usage rate: subgroup for countries}

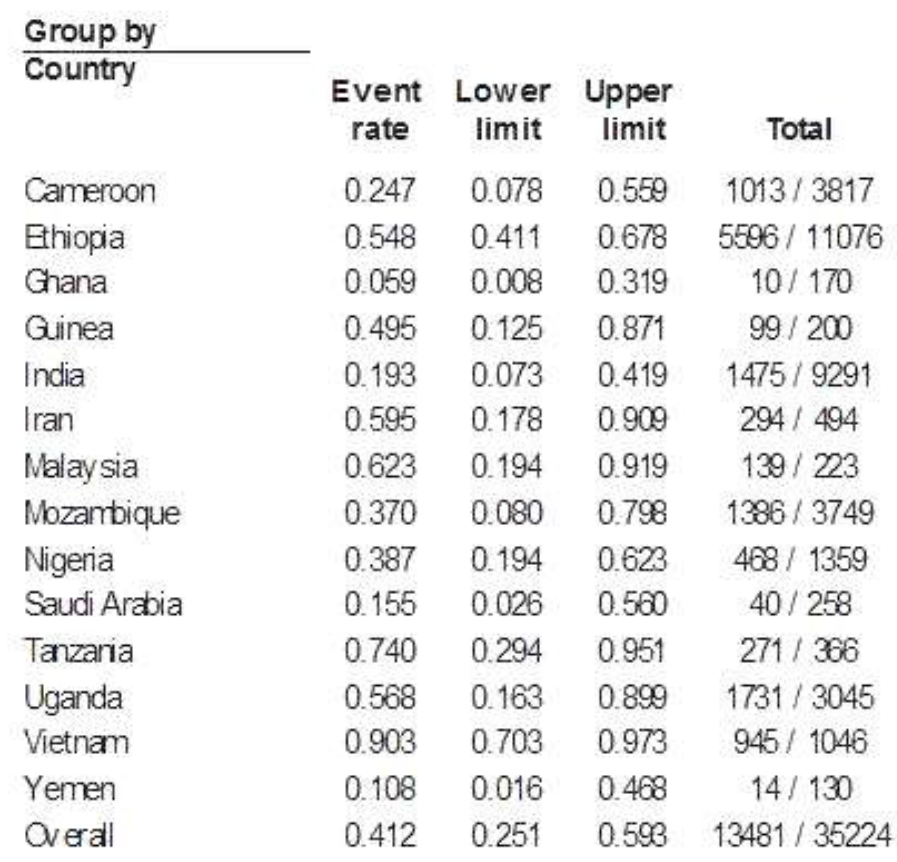
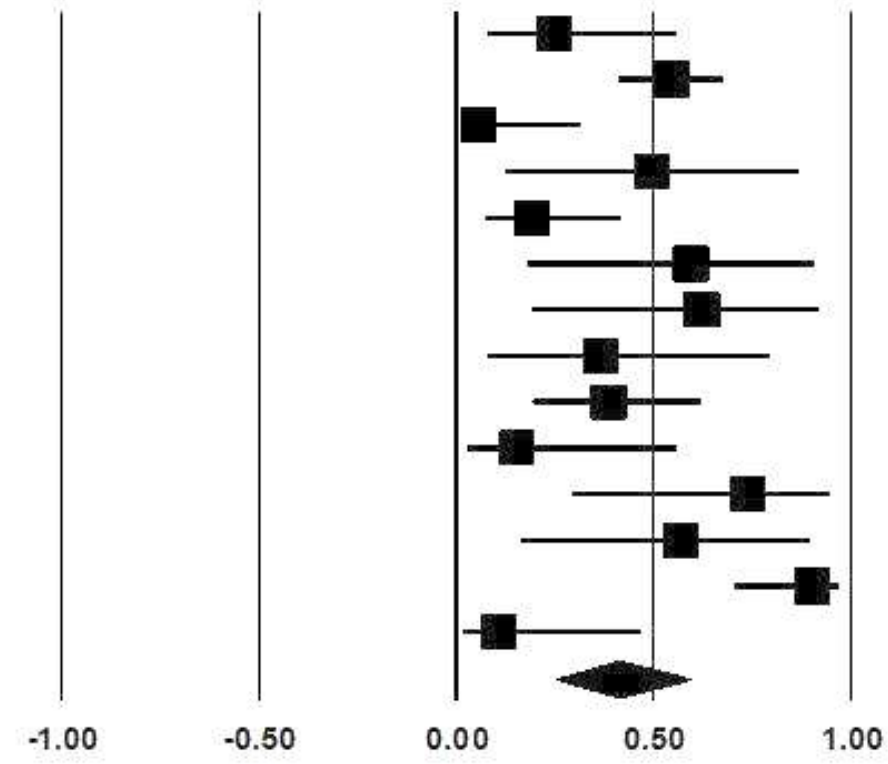

Figure 5

Meta-analysis for bed net individual usage rate: subgroup for countries. The analysis done among 14 countries that reported rates per individual study unit shows usage rate of bednets is highest in Vietnam but lowest in Ghana. The results are like household study unit which may indicate that the number of individuals using are same as numbers od household. Therefore, number of bed nets are equal to number of households, so each house owns one bed or amount of bed net distributed is one per household.

\section{Supplementary Files}

This is a list of supplementary files associated with this preprint. Click to download.

- SupplementaryTables.docx

- SupplementaryFigures.docx 